\title{
Implications of the atmosphere-soil interaction for the design of earth retaining structures
}

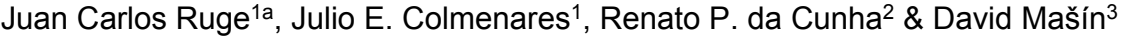 \\ ${ }_{2}^{1}$ Universidad Nacional de Colombia, Bogotá D.C. \\ ${ }_{3}^{2}$ University of Brasilia, Brasilia \\ ${ }^{3}$ Charles University, Prague.
}

\begin{abstract}
The performance of most geotechnical structures is highly governed by environmental factors, particularly in tropical regions where there are very pronounced dry and wet seasons. Design of earth retaining structures generally tend to be too conservative due to the uncertainty generated by the incorporation of environmental variables. Those variables control the soil unsaturated response and in addition to the known insufficiency of the basic models used in traditional designs they are responsible for conservative designs. Rainfall is the main aspect that affects the soil properties of a particular site. It modifies the soil suction potential, according to the degree of saturation caused by the soil-atmosphere interaction. Currently, state-of-the-art numerical tools allow to simulate the influence of those variables in the behaviour of earth retaining structures. This paper analyses the possible implications of the use of numerical simulations for the design, which include, in the mathematical formulation, the suction as a main parameter. The hypoplastic model for unsaturated response was used. Numerical simulations performed with the use of traditional and modern constitutive models obtained encouraging results that reveal the importance of include suction in design processes.
\end{abstract}

a jcruge@unal.edu.co 


\section{Introduction}

Various kind of geotechnical structures have their behaviour dependant on environmental variables such as their own configuration and interaction between elements and soil, especially those that are exposed to rain (i.e. slopes, excavations, embankments, fillings, etc.)

These conditioning factors make the structures have a critical condition during the most of its useful life, since in short-term load solicitations and excess of water porepressure control the response, and in long-term the environmental aspects can affect the soil behaviour. Likewise, the designers have considered these variables in their computations, but there is an uncertainty involved due to the nature of the environmental factors. This uncertainty is reflected in the overestimation of geotechnical parameters [1].

The objective of this research is to analyse the possible implications in design, considering the unsaturated response of the soil in excavations. Through numerical tools that include the rainfall effect in the computational model, as well as the influence on the suction and on the effective stress, was observed the evolution of hypoplastic unsaturated parameters [2] that can be implied in the design of these kind of structures. Also, the useful life of the project is considered on the results, since some retaining structures may be conceived as temporary or permanent prior to design stage.

\section{Methodology}

\subsection{Site Analysis}

The site chosen for this study was located at the SHN (Setor Hoteleiro Norte) of Distrito Federal (Brasilia), where it is possible to identify two geotechnical levels, according to soil investigations. The first layer of around 11 meters is composed by collapsible porous red clay with silt and gravels contents of soft to medium consistency, underlined for clayey silt with lens of sand medium to hard. The retaining structure in the analysis section consisted in a tangent pile curtain of 18 meters of length, 60 centimeters of diameter and embedding depth of 5 meters. Also the contention is reinforced by means of soil nailing.

The relative area of the retaining structure has a characteristic profile of the clayey red lateritic soil layer, so-called Brasilia porous clay. This material presents low strength to penetration ( $N_{S P T}$ 1-6 blows), low strength tip ( $C P T$ varying of 0.6 to $2.3 \mathrm{MPa}$ ), low bearing capacity, low level of saturation and high permeability $\left(10^{-3}\right.$ to $10^{-4}$ $\mathrm{m} / \mathrm{s}$ ), (details in [3]).

Due to the high porosity and kind of cementation, it presents a structure highly unstable when is subjected to increased wetting and/or alteration of stress state, presenting almost always a significant reduction of volume, denominated collapse [4].

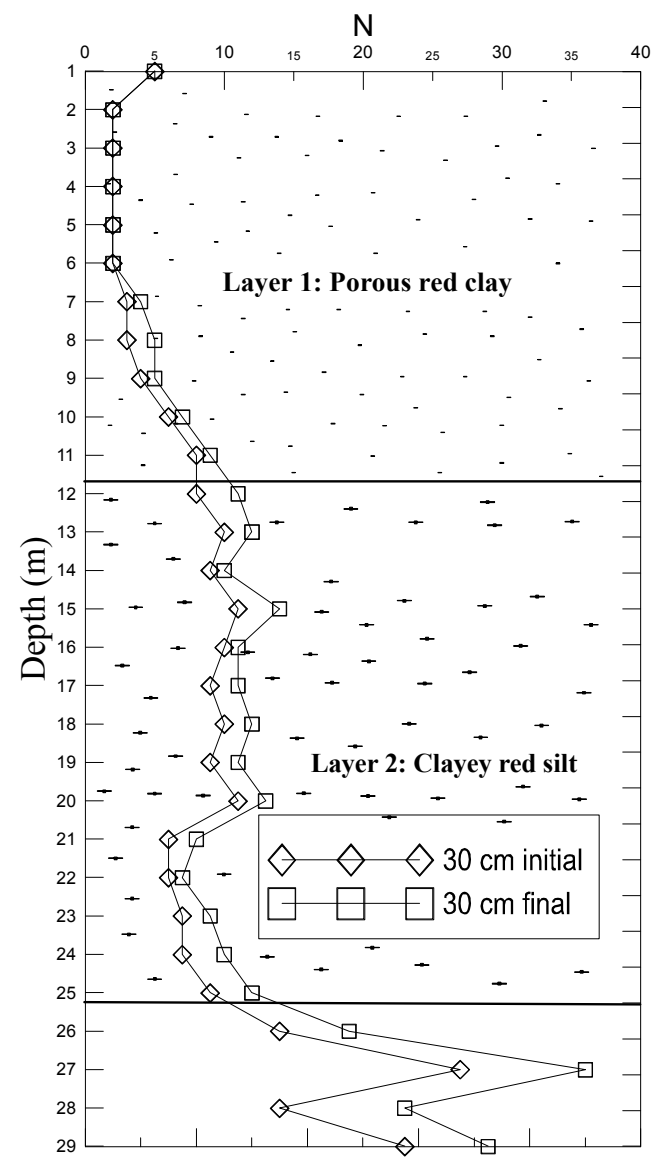

Figure 1. SPT results at the site.

\subsection{Characterization of the material}

It is obvious that an analysis involving atmosphere-soil interaction requires a more demanding characterization of the soil in terms of mechanical and hydraulic behaviour. For this reason is necessary to carry out, a series of basic and special tests in order to obtain parameters important to reproduce the unsaturated response of the soil in an adequate way. Some of those tests will be discussed below.

\subsubsection{Basic index characterization}

In order to obtain the basic characterization, index tests were performed on disturbed samples, as it is shown in Table 1.

Table 1. Basic characterization of the material

\begin{tabular}{ccc}
\hline Sample & $1 \mathrm{~B}$ & $2 \mathrm{~A}$ \\
\hline Depth $(\mathrm{m})$ & 6,0 & 9,0 \\
$w(\%)$ & 26,8 & 19,6 \\
$\gamma_{s}\left[\mathrm{kN} / \mathrm{m}^{3}\right]$ & 28,01 & 28,02 \\
$\gamma_{d}\left[\mathrm{kN} / \mathrm{m}^{3}\right]$ & 11,39 & 12,88 \\
$\gamma\left[\mathrm{kN} / \mathrm{m}^{3}\right]$ & 14,70 & 15,51 \\
$G s$ & 2,81 & 2,82 \\
$\mathrm{LL}(\%)$ & 48 & 50 \\
$\mathrm{PL}(\%)$ & 29 & 30 \\
$\mathrm{IP}(\%)$ & 19 & 20 \\
IC & 1,13 & 1,55 \\
\hline
\end{tabular}

\footnotetext{
a jcruge@unal.edu.co
} 


\subsubsection{Microstructure characterization}

In this regard, it is also important to define the microstructure predominance in the soil, since much of the suction potential is dictated by the presence of macropores or micropores in the system. Through a Mercury Intrusion Porosimetry test, the Pore Size Distribution (PSD) was obtained; it shows the large amount of macropores indicated by the peak in Figure 2 .

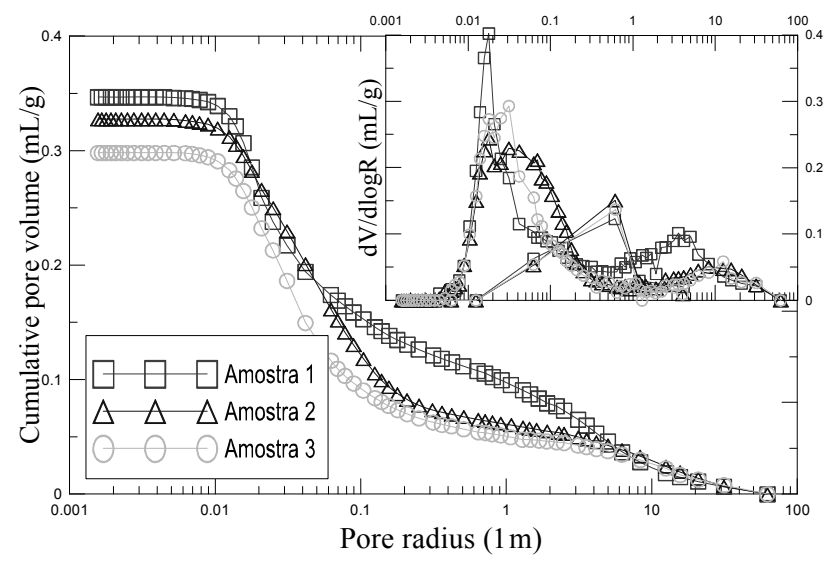

Figure 2. Pore size distribution (PSD) in the sample.

The typical particle size distribution was obtained too, showing the bimodal behaviour characteristic of this kind of lateritic soil. The real distribution depends of the use of deflocculant in the sample, as the actual granulometry results are shown in Figure 3.

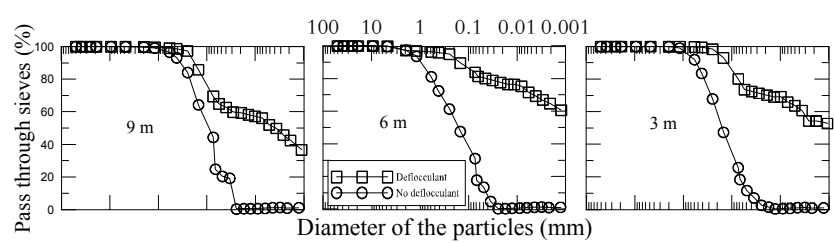

Figure 3. Particle size distribution in the samples

\subsubsection{Geotechnical characterization (strength tests)}

Regarding to the strength tests, the objective of the research is related with finding the initial unsaturated response in unaltered samples, and then trying to correlate with the mechanical behaviour of a retaining structure using a numerical tool. The results of unsaturated triaxial tests for different levels of suction are shown in Figure 4. Results demonstrated the suction phenomenon, at least in laboratory terms.
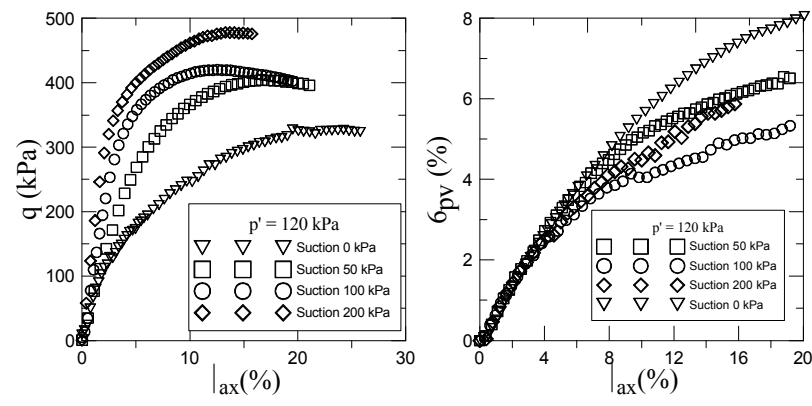

Figure 4. Unsaturated triaxial test on sample $(9 \mathrm{~m})$

\subsection{Reference constitutive model}

This previous stage of the numerical modelling is based in the analysis of the reference constitutive model. The model selected was the hypoplasticity for the mechanical response of unsaturated soils. The constitutive equations of this law were developed based on a critical state concept and the effective stress principle, considering the effect of increasing stiffness, governed by the variation of the suction on the mechanical response and the collapse phenomenon by wetting [5].

\subsubsection{Constant suction model}

The current reference model is supported in the concept proposed by [5]. The phenomenon of suction occurs inside of the soil skeleton influencing the effective tension and the normal forces on the interparticle contacts increasing the stiffness of the soil, since the particles are closer to each other. In other terms, this behavior increases the state boundary stress $(S B S)$ analogously, like are bonded the soil particles in cemented saturated geomaterials [6].

Therefore, the $S B S$ size for unsaturated soils is controlled by the NCL (Normal Compression Line) based on the Butterfield compression law [7], for the critical state line as it is showed in equation 1.

$\ln (1+e)=N(s)-\lambda^{*}(s) \ln \frac{p}{p_{r}}$

In equation $1 e$ is the void ratio, denoted like state variable in the constitutive law. The expressions $N_{(s)}$ and $\lambda^{*}{ }_{(s)}$ reproduce the position of the inclination of the virgin line compression in the space $\ln \left(p / p_{r}\right)$ vs $\ln (1+e)$ for a suction $s$. The model parameters $N$ and $\lambda^{*}$ define the values for saturated conditions.

Equation 2 defines the expression for equivalent tension of Hvorslev on the NCL for a given suction [8].

$p_{e}=p_{r} \exp \left[\frac{N(s)-\ln (1+e)}{\lambda^{*}(s)}\right]$

[9] Adjusted the values of the barotropy $f_{s}$ and picnotropy $f_{d}$ (eq. 3), since revealed that the inclusion of the virgin compressibility in the intercept $N_{(s)}$, affects the first values proposed by Gudehus (1996).

$$
f_{d}=\left(\frac{2 p}{p_{e}}\right)^{\alpha}
$$

$p_{e}$ is estimated by using the equation 2 , and the barotropy factor is:

$f_{s}=-\frac{\operatorname{tr} \mathrm{T}}{p_{e}}\left(3+a^{2}-2^{\alpha} \sqrt{3}\right)^{-1}$ 
The scalar factor $\alpha$ is in function of the parameters $\lambda^{*}$ and $\kappa^{*}$. Information about this variable can be consulted in [5], as well as for factor $a$.

\subsubsection{Model for any state of overconsolidation}

These considerations are used to complement the constitutive law for any state and load solicitation:

$-\square$ The suction controls the stability of contacts between particles, increasing the suction under constant effective tension.

$-\square$ The more open is the soil structure, the lower is the number of interparticle contacts; hence, each contact must transmit larger shear forces [5].

$\stackrel{\circ}{\mathrm{T}}=f_{s}\left(L: \mathrm{D}+f_{d} \mathrm{~N}\|\mathrm{D}\|\right)+f_{u} \mathrm{H}$

With

$\mathrm{H}=\frac{\mathrm{T}}{p_{e}} \frac{\partial p_{e}}{\partial s}\langle\dot{s}\rangle$

Where $s$ is introduced to study the first consideration, and $f_{u}$ the new picnotropy factor that controls the collapse in the soil, reproduce the second. When the factor is 1 the stress state is in the SBS (in this case the structure is as open as possible and the collapse being controlled by $\mathbf{H}$ only).

Instead $f_{u}$ tends to zero for $O C R=p_{e} / p$ (no wetting induced interparticle slippage occurs in highly overconsolidated soil). The following expression for the factor $f_{u}$ satisfying these requirements is proposed:

$$
f_{u}=\left(\frac{p}{p^{S B S}}\right)^{m}
$$

Where $p^{S B S}$ is the effective mean stress at the SBS corresponding to the current normalized stress $\mathbf{T} / \operatorname{tr} \mathbf{T}$ and the current void ratio $e$. Likewise, $m$ is a model parameter governing the influence of overconsolidation on the wetting-induced collapse.

\subsubsection{Parameters of the model}

Besides the parameters of the hypoplastic model for saturated soils $\left(\phi_{c}, N, \lambda^{*}, \kappa^{*}, r\right)$. The extension of the proposed model needs to consider the influence of the suction on $N$ and $\lambda$, respectively denoted as $N_{(s)}$ and $\lambda_{(s)}$.

$m$ controls the collapse of the structure along the wetting paths and $s_{e}$ is the value of suction at the air entry and/or air expulsion.

Similarly, $n$ and $l$ are scalar quantities included inside of the formulation of $N_{(s)}$ and $\lambda_{(s)}$ controlling the unsaturated NCL [5].

$$
\begin{aligned}
& N(s)=N+n \ln \left(\frac{s}{s_{e}}\right) \\
& \lambda^{*}(s)=\lambda^{*}+l \ln \left(\frac{s}{s_{e}}\right)
\end{aligned}
$$

\subsubsection{Calibration of the parameters}

It is necessary to adjust the parameters obtained at the lab through the constitutive law selected for the numerical phase. The calibration of the saturated parameters $\left(\lambda^{*}, \kappa^{*}\right.$ and $N$ ) are shown in Figure 5 [2]. The friction angle of the critical state is obtained $\left(\phi_{c}\right)$ of results of the strength peak in triaxial tests.

The unsaturated parameters $m, l$ and $n$ of the model can be computed from the saturated and unsaturated normal compression line, using isotropic compression tests and the equations 8 and 9 .

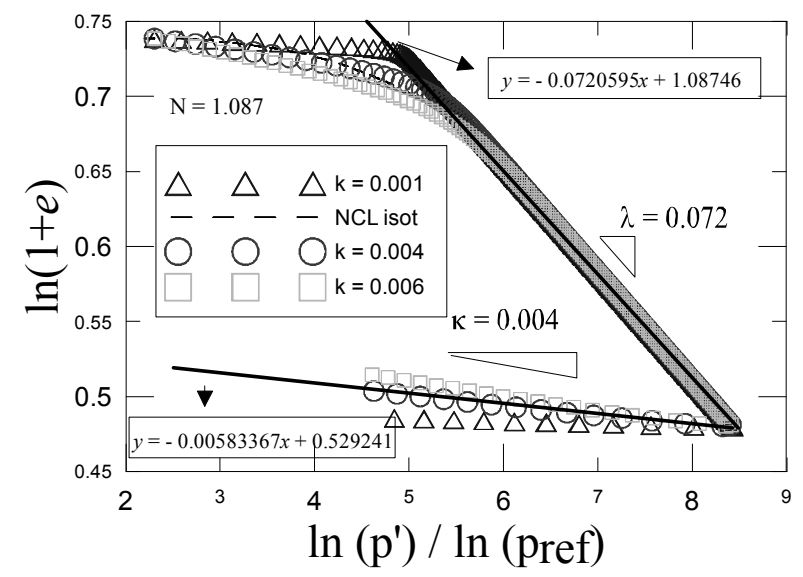

Figure 5. Calibration of the parameters $\lambda^{*}, \kappa^{*}$ and $N[2]$

\subsection{Numerical predictions}

One of the main challenges of the designer is about trying to predict the behaviour of the geotechnical structures by means of numerical tools. The essence of the matter consists in anticipating, at least in a qualitative way, the mechanical response of the soil or geotechnical elements before construction. However, it is also valid to have continuous complements for certain kind of structures as deep excavations, which require periodic control during the excavation sequences.

Table 2 shows the classification of predictions according the moment of occurrence.

Table 2. Predictions in geotechnical structures [10]

\begin{tabular}{ccc}
\hline Prediction & $\begin{array}{c}\text { Moment in } \\
\text { the event }\end{array}$ & Results \\
\hline $\mathrm{A}$ & Before & --------- \\
$\mathrm{B}$ & During & Unknown \\
$\mathrm{B} 1$ & After & Known \\
$\mathrm{C}$ & After & Known \\
$\mathrm{C} 1$ & After & Known \\
\hline
\end{tabular}


In this case, the numerical predictions involve not only specific factors about the behaviour of the soil, but also external variables as environmental factors (i.e. rainfall), which govern the global behaviour of the excavation under analysis.

To get an adequate approach including different factors, it is necessary to use a modern constitutive model that reproduce variables like suction, cementation, stress history, among others, into the numerical implementation.

\subsubsection{Computational model}

Fitting an appropriate computational model is a key job in the numerical modelling step. It is important to consider substantial aspects and to discard some that are not essential in the simulation [11].

Figure 6 shows the computational model developed for the geotechnical problem under analysis. The numerical modelling was performed taking into account the atmosphere-soil interaction, inserting real rainfall at the site. It is important to mention that the software also considers the soil water characteristic curve (SWCC) of the material, whereby it is possible to know the suction changes during the excavation affected by the rainfall too.

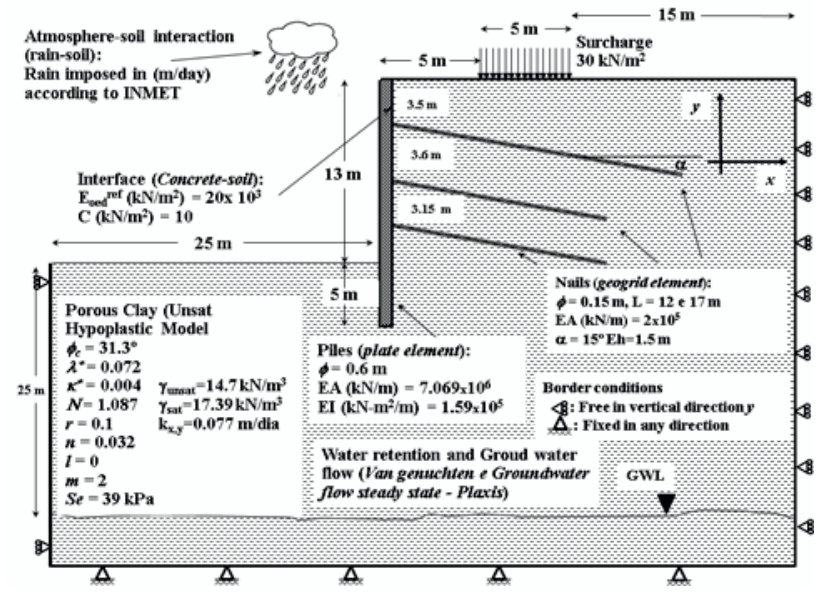

Figure 6. Computational model of the geotechnical problem

The groundwater level is located at $25 \mathrm{~m}$ deep from the last level of excavation. The position of the GWL indicates the high susceptibility of the upper layer to develop suction in a dry season, in the site under study.

\section{Results}

The results of the predictions were compared with the real behaviour of the retaining structure, monitored by means of instrumentation to control the deformations of the structure. Figure 7 shows the deformations occurred in the retaining during the period of instrumentation (223 days), as well as the numerical predictions (rain and dry).
These predictions were developed just to consider the atmosphere-soil interaction in the geotechnical problem (rain prediction). In the case of the dry prediction, a global retaining structure was simulated to observe the capacity of the constitutive model to take in account the suction. Rain prediction is a realistic scenario, while the dry prediction is conservative (high suction).
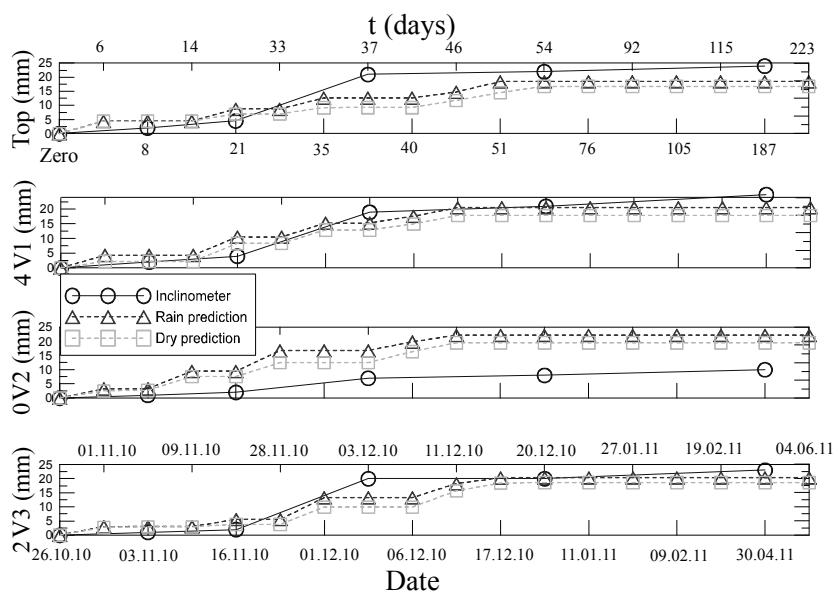

Figure 7. Instrumentation and numerical predictions in the geotechnical problem selected.

Figure 8 shows the deformations in the retaining structure measured by inclinometer (Inc) and modelled using a hypoplastic model (HP). This figure reveals the timedependent deformation in the retaining system, it is important to analyse the behaviour in relation with the timeline to understand the response in dry and raining season.

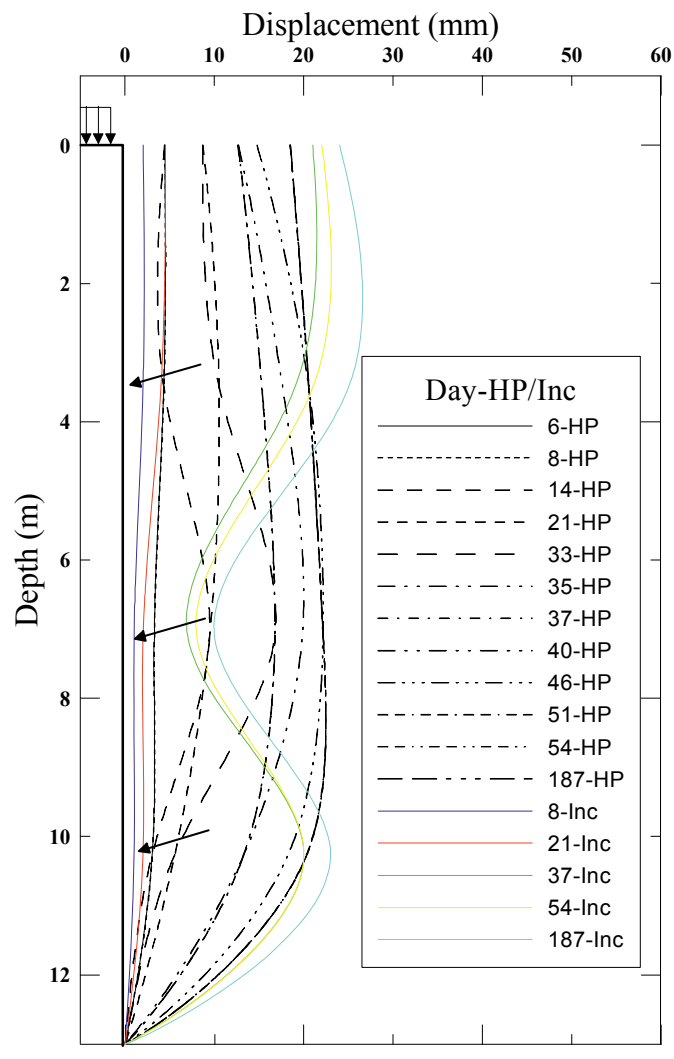

Figure 8. hstrumentation and numerical predictions in the geotechnical problem selected. 
Due to the fact that the main scope of this research was related with the implications in design of the unsaturated response of a retaining structure, it is important to analyse the problem using a traditional Mohr-Coulomb model. In Figure 9 shows a numerical simulation by means of the option " $\phi-c$ reduction" in the software. This option permits to reduce the geotechnical parameters until the failure of the material. The safety factor obtained for this option was 2 .

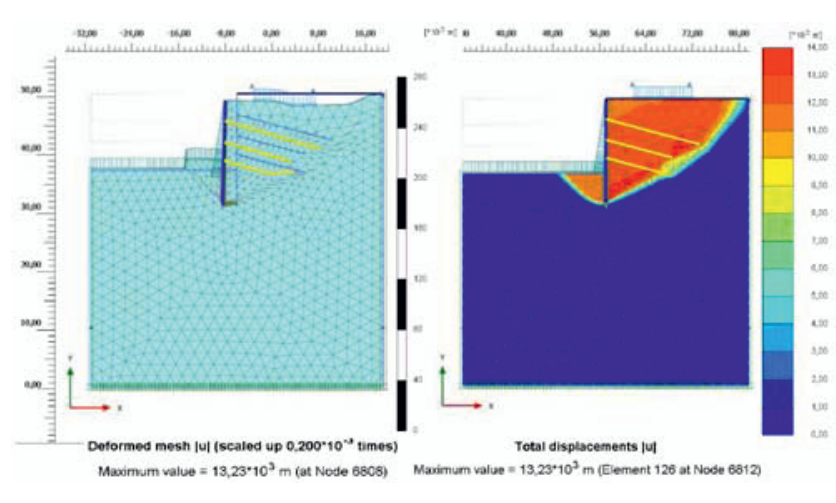

Figure 9. Prediction using Mohr-Coulomb mode.

\subsection{Analysis of the results}

It has always been evident in the geotechnical field that the designs are very conservatives due to the use of traditional constitutive models (i.e. no suction), which within their implementation overestimated parameters. The numerical simulation using " $\phi-c$ reduction", allows to reach such conclusions.

The modern constitutive models for unsaturated soils, which include suction into the mathematical implementation can be an essential tool in this kind of research. Some retaining structures are of temporary nature, due to the fact that their lateral loads are transferred to basement beams of the vertical structure at the end of the excavation.

In the dry season, the suction developed in the soil is higher. When the soil is close to be dry, the suction potential is very high, hence the effective stress and shear strength is also increased.

Therefore, building these structures during the dry period allows the design of retaining structures to be less conservative. Of course using more adequate geotechnical parameters. It is possible, as long as the constitutive model has within its implementation geotechnical parameters that simulate the unsaturated response of the soil.

\section{Conclusions}

The numerical predictions using modern constitutive models are an essential tool in the designing stage of any geotechnical project. However, consulting firms currently do not use this models since specialized tests, that are not time and cost efficient are required. Suction is a parameter that must be included in geotechnical designs, since it can offer a possibility to work with more realistic geotechnical scenarios.

The fact of building the retaining structure during the dry season must coincide with a susceptibility of the soil at the site, to generate high potential suctions by the atmosphere-soil interaction. In regions where there is a marked contrast between dry and raining seasons, it is easier to guarantee the time for the construction of retaining structures.

Some excavations are contained by using retaining structures as piles, diaphragm wall, sheetpiles, etc., reinforced with anchors, soil nailing, and shotcrete. Most numerical predictions show that in some cases it is not necessary to use additional engineering techniques to support the retaining structure.

\section{References}

1. $\square$ J.C. Ruge. Analise do comportamento de cortina de estacas executada em solo poroso metaestável mediante o uso de um modelo constitutivo hipoplástico considerando a resposta não saturada. PhD Thesis. University of Brasilia (2014).

2. $\square$ Ruge J. C., Cunha R. P. a Masin D. (2013). "Results of unsaturated tests on metastable soils". Advances in unsaturated soils. Proceedings of the First PanAmerican Conference on Unsaturated Soils, Cartagena, Colombia, pp. 469-474.

3. $\square$ R. Cunha, N. Jardim, and J. Pereira. In situ characterization of a tropical clay via dilatometer tests. Geo-Congress 99 on Behavior Characteristics of Residual Soils, ASCE Geotechnical Special Publication 92, Charlotte. 113-122 (1999).

4. $\square$ N. Mota. Ensaios avançados de campo na argila porosa não saturada de Brasilia: interpretação a aplicação em projetos de fundação. Ph.D. Thesis, University of Brasilia (2003).

5. $\square$ D. Mašín, and N. Khalili. A hypoplastic model for mechanical response of unsaturated soils. International Journal for Numerical and Analytical Methods in Geomechanics, 1(32), 1903-1926 (2008).

6. D. Mašín, and I. Herle. State boundary surface of a hypoplastic model for clays. Computers and Geotechnics, 6 (32), 400-410. (2005)

7. $\square$ R. Butterfield. A natural compression law for soils. Géotechnique, 29(4), 469-480. (1979).

8. $\square$ M. Hvorslev. Physical components of the shear strength of saturated clays. In Shear Strength of Cohesive Soils, proc. ASCE Research Conf. Boulder. (1960).

9. $\square$ D. Mašín. A hypoplastic constitutive model for clays with meta-stable structure. Canadian Geotechnical Journal, 44(3), 363-375. (2007).

10. T. Lambe. Predictions in soil engineering. Géotechnique, 23(2), 151-202. (1973).

11. D. Kolymbas. Advanced mathematical and computational geomechanics. Springer, $1^{\text {st }}$ ed (2003). 